\title{
Improved Antidepressant Remission in Major Depression via a Pharmacokinetic Pathway Polygene Pharmacogenetic Report
}

\author{
Ajeet B. Singh \\ Baycrest Biotechnology Pty Ltd, Victoria, Australia
}

\begin{abstract}
Objective: Major depressive disorder (MDD) is projected to be a leading cause of disability globally by 2030. Only a minority of patients remit with antidepressants. If assay of polymorphisms influencing central nervous system (CNS) bioavailability could guide prescribers to more effectively dose patients, remission rates may improve and the burden of disease from MDD reduce. Hepatic and blood brain barrier (BBB) polymorphisms appear to influence antidepressant CNS bioavailability.

Methods: A 12-week prospective double blind randomized genetically guided versus unguided trial of antidepressant dosing in Caucasian adults with MDD ( $n=148)$ was conducted.

Results: Subjects receiving genetically guided prescribing had a 2.52-fold greater chance of remission (95\% confidence interval $[\mathrm{Cl}]=1.71-3.73, \mathrm{z}=4.66, p<0.0001)$. The number needed to genotype $(\mathrm{NNG})=3(95 \% \mathrm{Cl}=1.7-3.5)$ to produce an additional remission. Conclusion: These data suggest that a pharmacogenetic dosing report (CNSDose ${ }^{\mathbb{R}}$ ) improves antidepressant efficacy. The effect size was sufficient that translation to clinical care may arise if results are independently replicated.
\end{abstract}

KEY WORDS: Pharmacogenetics; Pharmacogenomics; Individualized medicine; Antidepressive agents; Major depression.

\section{INTRODUCTION}

The World Health Organisation predicts that major depressive disorder (MDD) will become a leading cause of disability globally by $2030 .{ }^{1)}$ Reducing the burden of disease from MDD is a public health priority, yet it appears the per capita level of disability from MDD globally is increasing. ${ }^{2)}$ Antidepressants have assisted treatment of more severe MDD, with demonstrated superiority over placebo. ${ }^{3)}$ Unfortunately, $30-50 \%$ of patients do not respond (at least a halving of the depression rating scale score) ${ }^{4}{ }^{4}$ to their first antidepressant trial. ${ }^{5-10)}$ Remission (return of the rating scale to normative levels; e.g., 17-item Hamilton Depression Rating Scale [HDRS] 57 ) is clinically a more translatable efficacy measure as those who respond but fail to remit tend to relapse. ${ }^{4,11)}$ Remission not response is the pathway to recovery from MDD. ${ }^{12)}$ Antidepressant remission rates are even lower than those

\footnotetext{
Received: September 1, 2014 / Revised: January 4, 2015

Accepted: January 7, 2015

Address for correspondence: Ajeet B. Singh, MD

Baycrest Biotechnology Pty Ltd, MDPO Box 9148, St Albans Park, Victoria, Australia

Tel: +613-5248-7211, Fax: +613-5248-4767

E-mail: ajeetsingh@dodo.com.au
}

for response, as low as $37.5 \%$ according to a meta-analysis of 2,971 subjects. ${ }^{13)}$

It can take several months (even years) of clinical trial and error before an effective tolerable antidepressant is found for an individual patient. During this time patients remain exposed to the handicapping effects of their symptoms and the risk of acting on self-harm ideations. If affordable practical treatment biomarkers of sufficient effect size emerged, some of the trial and error in antidepressant prescribing could be eliminated. ${ }^{14,15)}$ Investigation for genetic treatment biomarkers for medication efficacy, tolerability, and safety (pharmacogenetics) is an active research front. ${ }^{16)}$ As pharmacogenetic testing becomes increasingly affordable, should such testing be robustly demonstrated to substantially improve antidepressant outcomes, widespread uptake may arise with potential public health benefits. ${ }^{16)}$ Only one prospective genetically guided versus unguided antidepressant trail has been conducted to date. In this study of 51 subjects with MDD a proprietary interpretive report demonstrated a trend for better outcomes in the genetically guided versus unguided group. ${ }^{17)}$ Larger more adequately powered double blind randomized controlled studies are needed to robustly shed light on the clinical utility of pharmacogenetic interpretive reports in the treatment of MDD.

(c) This is an Open-Access article distributed under the terms of the Creative Commons Attribution Non-Commercial License (http://creativecommons.org/licenses/by-nc/4.0) which permits unrestricted non-commercial use, distribution, and reproduction in any medium, provided the original work is properly cited. 
The exact mechanism(s) of action of antidepressants remains elusive. ${ }^{18-20)}$ There is evidence suggesting that Caucasian $l$ carriers at the serotonin transporter linked promoter region (5HTTLPR) are more likely to respond to antidepressants, ${ }^{21)}$ but the effect size appears too small for clinical utility. The association also appears to be modulated by environmental stress, putatively via epigenetic mechanisms. ${ }^{22,23)}$ Uncertainty about the mechanism of action of antidepressants probably impedes the identification of clinically useful pharmacodynamic pharmacogenetic treatment biomarkers. ${ }^{16)}$ More clearly understood are two key pharmacokinetic steps governing antidepressant central nervous system (CNS) bioavailability - the cytochrome P450 (CYP450) hepatic metabolism enzyme system and the active efflux transporters (ABC transporters) at the blood brain barrier (BBB). Collectively, these body 'defences' make it difficult for xenobiotics (including antidepressants) to reach the pristine cerebrospinal fluid (CSF) bathing the CNS. ${ }^{24)}$ Genetically mediated inter-individual variations in these key pharmacokinetic pathways may underscore the different antidepressant doses needed for patients to enjoy tolerable efficacy. $^{14-16,25,26)}$

Genetic variation affecting hepatic CYP450 metaboliser status has been demonstrated in CYP2D6 and CYP2C19 enzyme subtypes which are involved in the metabolism of most second generation antidepressants and commonly show functional variance between individuals. ${ }^{25)}$ Polymorphisms of CYP450 enzymes have been correlated to enzyme activity, enabling phenotype estimation from the related genotype into poor metaboliser (PM), intermediate metaboliser (IM), extensive metaboliser (EM), and more rarely ultrarapid metaboliser (UM). A 30-70\% dose reduction for PM patients and a $135-180 \%$ dose elevation in UM patients prescribed CYP2D6 and CYP2C19 dependent antidepressants has been proposed. ${ }^{25,27)}$ One second generation antidepressant (desvenlafaxine) is not subject to such phase I CYP450 metabolism ${ }^{28}$; , however, it is subject to metabolism by the phase II hepatic enzyme UGT1A1 (uridine 5'-diphospho-glucuronosyltransferase) for which only $10 \%$ of subjects have rapid metaboliser status. ${ }^{29)}$ One may expect less inter-individual dose variance for desvenlafaxine given this, but the dose range in clinical settings is large. ${ }^{30)}$ This may in part be explained by inter-individual differences in BBB transporter systems-the other key pharmacokinetic 'hurdle' for many antidepressants.

Various active transporters appear to impede entry of antidepressants into the brain. ${ }^{24,31,32)}$ The first identified- the ABCB1 transporter - was discovered during study of chemotherapeutic resistance in hamster cancer cells. The involved permeability glycoprotein was then named the P-glycoprotein. ${ }^{33)}$ Nearly a decade later the human coding gene was identified on chromosome $7 \mathrm{q} 21.12 .^{34,35)}$ It is now known to be a member of a larger ATP-binding cassette family of transporter proteins involved in multidrug resistance. $^{32)}$ This family of transporters appears to be essential to life - highly conserved among species. ${ }^{36)}$ ABCB1 has been shown to be evenly expressed and functionally protective across the entire human brain. ${ }^{37)}$ It appears $\mathrm{ABCB} 1$ has a key role in the CNS bioavailability of several psychotropics. ${ }^{31)}$ The importance of $\mathrm{ABCB} 1$ in drug bioavailability was emphasised using human duodenal cells that showed the TT polymorphism of the rs1045642 single nucleotide polymorphisms (SNP) reduced ABCB1 efflux. ${ }^{38)}$ This is a synonymous SNP producing a codon that does not change the expressed amino acid (isoleucine). In a pivotal study utilising cultured human HeLa cell lines, TT genotype at rs 1045642 resulted in use of the rarer isoleucine codon (ATT rarer than ATC), altering $\mathrm{ABCB} 1$ conformational folding and through this mechanisms altering efflux functioning. ${ }^{39)}$

Studies with $a b c b 1$ knockout mice have demonstrated that citalopram, escitalopram, paroxetine, sertraline, venlafaxine, desvenlafaxine, reboxetine, doxepin, amitriptyline and trimipramine, are substrates for ABCB1; however, fluoxetine, mirtazapine, bupropion and melperone do not appear to be. ${ }^{40-43)}$ Four studies have found an association between $A B C B 1$ polymorphisms and differential symptom improvement with antidepressants subject to ABCB1 efflux. ${ }^{26,41,44,45)}$ A candidate gene association study suggested $A B C B 1$ rs1045642 polymorphisms predicted the dose of escitalopram needed to remit, with $\mathrm{C}$ carriers requiring double the dose. ${ }^{26)}$ Interestingly, polymorphisms of another $\mathrm{ABC}$ transporter gene $-A B C C 1-$ have also been implicated in antidepressant efficacy. ${ }^{46)} \mathrm{A}$ SNP of the 3' untranslated region of the $A B C C 1$ gene (rs212090) appears to influence $A B C C 1$ transcription $^{46)}$ and citalopram remission rates. The altered transcription mechanism may involve differential mRNA stability. ${ }^{47)}$ This may have functional effects on the ABCC1 transporter. Perhaps akin to the combined CYP450 2D6 and 2C19 genotype influencing antidepressant metabolizer status, combined $A B C B 1$ and $A B C C 1$ genotype may influence differential patient BBB permeability? Perhaps the combination of $A B C B 1$ rs 1045642 (C3435T) and $A B C C 1$ rs 212090 (3'T5463A) could be the pharmacogenetic keys to the BBB? 
A genetically guided versus unguided prospective double blinded randomized comparator study was conducted to investigate the clinically utility of a pharmacokinetic pathway polygene pharmacogenetic interpretive report $\left(\mathrm{CNSDose}^{\mathrm{R}}\right)$ which takes into account both hepatic and BBB polymorphisms. Specifically, I hypothesized patients whose dose is adjusted according to the automated interpretive formula will have better remission rates, fewer days off work due to depression, and better antidepressant tolerability (fewer instances of side effects requiring dose reduction or medication cessation).

\section{METHODS}

DNA was extracted from patient self-administered buccal brush samples using QIAamp DNA Mini kit (QIAGEN Inc., Venlo, Netherlands). Genotype of candidate SNPs was determined by the polymerase chain reaction (PCR) followed by single primer extension and analysis on a Sequenom $^{\circledR}$ Matrix (Sequenom Inc., San Diego, CA, USA)-assisted laser desorption/ionization time-of-flight mass spectrometry (MALDI-TOF) 384 well genetic analysis system. For the large duplications and deletions standard long-range PCR was used.

Subjects received clinical care by their treating psychiatrist during the 12 week study period. Subjects with a principal DSM-5 diagnosis of MDD (semi-structured psychiatrist interview) were eligible. Subjects with other active psychiatric diagnoses were excluded, such as those suffering with adjustment disorders, psychosis, bipolar disorder, substance use disorders, and those with a principal diagnosis of a personality disorder. Pregnant or breastfeeding subjects were excluded. Subjects with hepatic or renal impairments were excluded as such could influence appropriate dosing. Subjects co-prescribed known CYP2D6, CYP2C19, or ABCB1 inducers/inhibitors; subjects regularly drinking grapefruit juice; and smokers were excluded as such may also influence appropriate dosing. ${ }^{48-51)}$ Age, sex, duration of depressive episode, and number of depressive episodes was recorded as well as baseline 17-item HDRS score. Only subjects with HDRS scores over 18 were included - given moderate to severe depression only has robust evidence of antidepressant efficacy. ${ }^{3)}$ As the literature on pharmacogenetics suggests possible inter-ethnic variations, only Caucasian subjects were recruited to avoid ethnicity becoming a potential confounder.

All subjects had a buccal brush sample obtained, but via computerized randomization only half had this information analysed and a report sent to their prescriber. Many yet to be determined factors (genetic and non-genetic) may influence optimal dosing, thus randomization is essential to help balance out potential confounding factors between groups. As all subjects provide buccal brush samples, patients were blind to which study group they were in. Antidepressant remission rates were assessed with baseline and 4 weekly HDRS over 12 weeks by an independent rater blinded to which group the patient belonged - genetically guided $(n=74)$ or unguided $(n=74)$. Thus, the study was double blinded - helping prevent patient or outcome assessor biases influencing outcome ratings. The prescriber did not inform the patient if a DNA report was being used in their prescribing, and could indicate (by confidential feedback form) if they elected to use the report information to guide dose and if so doing led them to dose medication differently from usual practice. The antidepressant prescribed was left to the judgement of prescriber and patient - based upon preferred side effect profile and avoidance of agents that had previously proven ineffective or intolerable. This helped ensure patient care was not disadvantaged. The pharmacogenetic interpretive report provided indicated if the patient's genotype suggested mid-range, high-range, or low-range doses were needed. Intolerability events where the patient needed to reduce the dose or stop their antidepressant were recorded for analysis. Finally, the number of sick days taken off from work or studies due to depression was recorded. Ethics approval was obtained from a National Health and

Table 1. Sample characteristics

\begin{tabular}{lcc}
\hline \multicolumn{1}{c}{ Characteristic } & Genetically guided dosing & Genetically unguided dosing \\
\hline Baseline HDRS & 24.81 & 24.66 \\
Average duration of MDD (mon) & 8.51 & 8.59 \\
Average number of MDD episodes & 2.22 & NS \\
Proportion male (\%) & 42 & 2.18 \\
Average age (yr) & 44.2 & 39 \\
Proportion employed (\%) & 91 & 44.3 \\
\hline
\end{tabular}

Clinical and socio-demographic characteristics stratified by genetically guided versus unguided prescribing. No significant difference in the above listed characteristics were identified.

HDRS, 17-item Hamilton Depression Rating Scale; MDD, major depressive disorder; NS, not significant at p=0.05 level. 
Medical Research Council (Australia) approved ethics committee (ACTRN12613001135707). IBM SPSS Statistics software (version 22.0; IBM Co., Armonk, NY, USA) was used in the analysis of the data, results expressed as risk ratios (RR) with $95 \%$ confidence interval $(\mathrm{CI})$ and number need to genotype (NNG) values to readily communicate significance and magnitude of any findings. ${ }^{52)}$ NNG is the number of people that needed the test for an additional patient to remit from MDD. $T$-tests were used to compare differences in averages between groups.

\section{RESULTS}

A total of 174 patients were screened for eligibility. A total of 22 subjects were excluded: 12 had a principal diagnosis other than MDD and 10 had a baseline HDRS score $<18$. The remaining 152 subjects were randomised to either genetically guided or unguided prescribing, but 4 sub-

Table 2. Medication type by group

\begin{tabular}{lccc}
\hline Antidepressant & $\begin{array}{c}\text { Genetically } \\
\text { guided dosing }\end{array}$ & $\begin{array}{c}\text { Genetically } \\
\text { unguided dosing }\end{array}$ & p-value \\
\hline Sertraline & 13 & 12 & NS \\
Escitalopram & 8 & 7 & NS \\
Paroxetine & 5 & 7 & NS \\
Fluoxetine & 6 & 7 & NS \\
Fluvoxamine & 2 & 3 & NS \\
Reboxetine & 3 & 5 & NS \\
Venlafaxine & 7 & 7 & NS \\
Desvenlafaxine & 5 & 4 & NS \\
Duloxetine & 5 & 6 & NS \\
Mirtazapine & 5 & 3 & NS \\
Agomelatine & 10 & 8 & NS \\
Clomipramine & 3 & 3 & NS \\
Nortriptyline & 1 & 1 & NS \\
Amitriptyline & 1 & 1 & NS \\
\hline
\end{tabular}

Choice of medication was at the discretion of the prescriber and subject. There were no significant differences in the frequencies of different antidepressants used between the genetically guided and unguided groups.

NS, not significant at the $p=0.05$ level. jects failed to attend for research follow-up. Thus, 148 subjects completed the study, unguided group $(\mathrm{n}=74)$ and genetically guided group $(\mathrm{n}=74)$ had data analysed for differential antidepressant efficacy and tolerability. Baseline and other characteristics of the sample are displayed in Table 1. Importantly, there were no significant differences in baseline HDRS score to confound findings. There were no significant differences in the antidepressants used between the two groups (Table 2).

The pharmacogenetic interpretive report was reviewed by the treating prescriber in $100 \%$ (74/74) of instances. This led to medication dosing different to usual practice by the prescriber $65 \%(48 / 74)$ of the time. Table 3 displays the key study findings. The genetically guided group was 2.52 times more likely to remit from MDD $(95 \% \mathrm{CI}=$ 1.71-3.73, $\mathrm{z}=4.66, p<0.0001)$ than the unguided group, with NNG for remission from MDD $=3(95 \%$ CI 1.7-3.5). The unguided group were 1.13 times more likely to have medication tolerability problems $(95 \% \mathrm{CI}=1.01-1.25$, $\mathrm{z}=2.208, p=0.0272)$ requiring either dose reduction or cessation. The genetically guided group had significantly less risk of taking sick leave ( $4 \%$ versus $15 \%, p=0.0272$ ) and significantly less duration of sick leave when such was needed ( 4.3 days versus 7.7 days, $p=0.014$ ).

\section{DISCUSSION}

This study is the first statistically significant positive double blind randomized genetically guided versus unguided prospective comparator trial suggesting a pharmacogenetic interpretive report improves antidepressant efficacy through a dose guidance report. As remission not response is the pathway to recovery from $\mathrm{MDD},{ }^{12)}$ the finding of markedly improved remission rates ( $72 \%$ versus $28 \%$ ) in the genetically guided group may have clinical translation implications should findings be independently replicated. The remission rate in the genet-

Table 3. Differential antidepressant efficacy and tolerability by group

\begin{tabular}{|c|c|c|c|c|}
\hline Variable & Remission rate & Intolerability rate & Proportion taking sick leave & Average sick days \\
\hline $\begin{array}{l}\text { Genetically guided } \\
\text { dosing }\end{array}$ & $\begin{array}{c}72 \% \\
R R=2.52(95 \% \mathrm{Cl}=1.71-3.73 \\
z=4.660, p<0.0001) \\
N N G=3(95 \% \mathrm{Cl}=1.7-3.5)\end{array}$ & $4 \%$ & $4 \%$ & $4.3(p=0.014)$ \\
\hline $\begin{array}{l}\text { Genetically unguided } \\
\text { dosing }\end{array}$ & $28 \%$ & $\begin{array}{c}15 \% \\
R R=1.13(95 \% C l=1.01-1.25 \\
z=2.208, p=0.0272) \\
N N G=10(95 \% C l=5.0-64.8)\end{array}$ & $\begin{array}{c}15 \% \\
R R=1.13(95 \% C l=1.01-1.25 \\
z=2.208, p=0.0272)\end{array}$ & 7.7 \\
\hline
\end{tabular}

The genetically guided group had significantly greater remission rates, better tolerability, and fewer sick days from work. Those subjects treated with genetically guided dosing had a 2.52-fold greater chance of remission form MDD (HDRS $\leq 7$ ) and a 1.13 -fold reduced risk of medication intolerability (dose reduction or cessation needed).

RR, risk ratio; NNG, number needed to genotype; HDRS, 17-item Hamilton Depression Rating Scale; MDD, major depressive disorder. 
ically guided group is nearly double that found in current (genetically unguided) practice. $^{13)}$ The reduced rate of sick leave and reduced sick leave duration in the genetically guided group may have health economic implications, particularly given the reducing costs of genotyping and the fact that only one pharmacogenetic test per patient lifetime is needed.

Relatively recently, mechanistic understandings of how $\mathrm{ABCB} 1$ and $\mathrm{ABCC} 1$ may act in concert have emerged. These mechanisms might explain why the combination of functional polymorphisms from these transporters led to predictive power of the polygene panel (CNSDose $\left.{ }^{(}\right)$used in this study. ABCB1 appears to be expressed on the blood (luminal) side of BBB endothelia, whereas ABCC1 appears to be expressed on the CSF (abluminal) side of the $\mathrm{BBB}{ }^{53-55)}$ It appears that endogenous inhibitors of $\mathrm{ABCB} 1$ are transported into $\mathrm{BBB}$ endothelia by $\mathrm{ABCC} 1{ }^{56-59)} \mathrm{As}$ $\mathrm{ABCB} 1$ and $\mathrm{ABCC} 1$ have similar substrate affinities, ${ }^{60)}$ should a toxin impede the function of both transporters, the reduced functioning of $\mathrm{ABCC} 1$ will result in reduced transport by $\mathrm{ABCC} 1$ of $\mathrm{ABCB} 1$ endogenous inhibitors, enabling greater activity of $\mathrm{ABCB} 1$ in real time to defend the CNS against toxins. This putative mechanism may help explain the finding of Lee et al. ${ }^{46)}$ - polymorphisms of $A B C C 1$ gene lead to reduced expression of $\mathrm{ABCC} 1$ and were thus potentially associated with greater $\mathrm{ABCB} 1 \mathrm{ac}-$ tivity and greater pharmacokinetic blockade at the $\mathrm{BBB}$ of paroxetine, explaining the reduced clinical remission rates noted in that study. The existence of both an association to differential antidepressant efficacy, differential mRNA levels of the transporters, and a mechanism linking the roles of $\mathrm{ABCB} 1$ and $\mathrm{ABCC} 1$ makes functional polymorphisms of these two BBB transporters prime candidates for a pharmacogenetic treatment biomarker panel. This may explain the significant finding and large effect size of the current study. Failure of previous pharmacogenetic studies to control for the influence of phase I hepatic metabolism genotype, phase II hepatic metabolism genotype, ABCB1 transporter genotype, and ABCC1 transporter genotype may explain the mixed findings in the literature to date - which has mainly consisted of association studies. $^{16,61,62)}$

The other main strength of this study is the randomized double blind design. Candidate gene association studies have the major drawback of not being able to control for unknown confounders. ${ }^{16)}$ The advantage of randomization (in large enough samples) is the inherent balancing out between groups of covariates, helping reduce the risk of confounding factors distorting findings. If the current study finding is independently replicated in similar or larger samples, use of pharmacogenetic testing in the treatment of MDD may start to enter clinical practice more widely upon appropriate regulator approval. The burden of disease from MDD could be significantly reduced through less trial and error dosing. Rapid turn around time (TAT) of genetic testing will be needed for clinical uptake, as long delays between testing and reporting will impeded clinical uptake. In the current study TAT of 5-10 days enabled clinical integration of the report.

The current study does have some importantly limitations. Firstly, the exclusion of patients with co-morbidities may limit the application of these findings to larger real world clinical settings where co-morbidity is common. Secondly, as the study involved Caucasian subjects only-the relevance of findings to other ethnic groups in unclear. A further issue is whether the selected polygene panel is the best. Only head to head trials with other pharmacogenetic interpretive reports will answer this question, but large samples will be needed to shed light on small differences between pharmacogenetic reporting systems. Importantly, epigenetic and environmental factors were not included in this study. Inclusions of such may provide enhanced predictive power. Finally, larger sample sizes would help further reduce the risk of type I error mediating the findings in this study. Independent replication will be required to minimise both risk of type I error and biases from individual studies such as the current one. It is hoped the current study will stimulate other groups to consider replication. Should such replication be positive, this may pave the way for clinical implementation. This appears to be particular relevant now as it appears psychiatrists are anticipating genetically guided prescribing to become the standard of care. ${ }^{63)}$

In conclusion, the proprietary pharmacokinetic polygene pathway pharmacogenetic interpretive formula and dosing report used in this study (CNSDose ${ }^{\mathbb{R}}$ ) has the first methodologically robust statistically significant empirical evidence for marked clinical utility of a pharmacogenetic test and dosing report in the antidepressant treatment of MDD. If these findings are independently replicated, a priori antidepressant pharmacogenetic testing may start to enter clinical practice guidelines. As whole genome sequencing becomes more affordable, many patients may started to already have the needed polymorphism information on file - eliminating TAT and added test cost issues. The improved antidepressant efficacy that results from pharmacogenetic reporting may help reduce the burden of disease from MDD. 


\section{REFERENCES}

1. Mathers CD, Loncar D. Projections of global mortality and burden of disease from 2002 to 2030. PLoS Med 2006;3: e442.

2. Murray CJ, Vos T, Lozano R, Naghavi M, Flaxman AD, Michaud C, et al. Disability-adjusted life years (DALYs) for 291 diseases and injuries in 21 regions, 1990-2010: a systematic analysis for the Global Burden of Disease Study 2010. Lancet 2012;380:2197-2223.

3. Fournier JC, DeRubeis RJ, Hollon SD, Dimidjian S, Amsterdam JD, Shelton RC, et al. Antidepressant drug effects and depression severity: a patient-level meta-analysis. JAMA 2010;303:47-53.

4. Nierenberg AA, DeCecco LM. Definitions of antidepressant treatment response, remission, nonresponse, partial response, and other relevant outcomes: a focus on treatment-resistant depression. J Clin Psychiatry 2001;62 Suppl 16:5-9.

5. Moncrieff J, Kirsch I. Efficacy of antidepressants in adults. BMJ 2005;331:155-157.

6. Trivedi MH, Rush AJ, Wisniewski SR, Nierenberg AA, Warden D, Ritz L, et al. Evaluation of outcomes with citalopram for depression using measurement-based care in STAR*D: implications for clinical practice. Am J Psychiatry 2006; 163:28-40.

7. Amsterdam JD, Hornig-Rohan M. Treatment algorithms in treatment-resistant depression. Psychiatr Clin North Am 1996; 19:371-386.

8. Greden JF. The burden of disease for treatment-resistant depression. J Clin Psychiatry 2001;62 Suppl 16:26-31.

9. hase ME, Haight BR, Richard N, Rockett CB, Mitton M, Modell JG, et al. Remission rates following antidepressant therapy with bupropion or selective serotonin reuptake inhibitors: a meta-analysis of original data from 7 randomized controlled trials. J Clin Psychiatry 2005;66:974-981.

10. Rush AJ, Trivedi MH, Wisniewski SR, Nierenberg AA, Stewart JW, Warden D, et al. Acute and longer-term outcomes in depressed outpatients requiring one or several treatment steps: a STAR*D report. Am J Psychiatry 2006; 163:1905-1917.

11. Nierenberg AA, Wright EC. Evolution of remission as the new standard in the treatment of depression. J Clin Psychiatry 1999;60 Suppl 22:7-11.

12. Frank E, Prien RF, Jarrett RB, Keller MB, Kupfer DJ, Lavori PW, et al. Conceptualization and rationale for consensus definitions of terms in major depressive disorder. Remission, recovery, relapse, and recurrence. Arch Gen Psychiatry 1991;48:851-855.

13. Thase ME, Nierenberg AA, Vrijland P, van Oers HJ, Schutte AJ, Simmons JH. Remission with mirtazapine and selective serotonin reuptake inhibitors: a meta-analysis of individual patient data from 15 controlled trials of acute phase treatment of major depression. Int Clin Psychopharmacol 2010; 25:189-198.

14. Singh A. Pharmacogenomics--the potential of genetically guided prescribing. Aust Fam Physician 2007;36:820-824.

15. Singh A, Berk M. Genetically guided prescribing: Hope or hype? Acta Neuropsychiatr 2008;20:50-51.

16. Singh AB, Bousman CA, Ng C, Berk M. Antidepressant pharmacogenetics. Curr Opin Psychiatry 2014;27:43-51.

17. Winner JG, Carhart JM, Altar CA, Allen JD, Dechairo BM. A prospective, randomized, double-blind study assessing the clinical impact of integrated pharmacogenomic testing for major depressive disorder. Discov Med 2013;16:219-227.
18. Shelton RC. Intracellular mechanisms of antidepressant drug action. Harv Rev Psychiatry 2000;8:161-174.

19. Malberg JE, Blendy JA. Antidepressant action: to the nucleus and beyond. Trends Pharmacol Sci 2005;26:631-638.

20. Belmaker RH, Agam G. Major depressive disorder. N Engl $J$ Med 2008;358:55-68.

21. Porcelli S, Fabbri C, Serretti A. Meta-analysis of serotonin transporter gene promoter polymorphism (5-HTTLPR) association with antidepressant efficacy. Eur Neuropsychopharmacol 2012;22:239-258.

22. Keers R, Uher R, Huezo-Diaz P, Smith R, Jaffee S, Rietschel $\mathrm{M}$, et al. Interaction between serotonin transporter gene variants and life events predicts response to antidepressants in the GENDEP project. Pharmacogenomics $J$ 2011;11:138-145.

23. Domschke K, Tidow N, Schwarte K, Deckert J, Lesch KP, Arolt V, et al. Serotonin transporter gene hypomethylation predicts impaired antidepressant treatment response. Int $J$ Neuropsychopharmacol 2014;17:1167-1176.

24. Dutheil F, Jacob A, Dauchy S, Beaune P, Scherrmann JM, Declèves $\mathrm{X}$, et al. ABC transporters and cytochromes $P 450$ in the human central nervous system: influence on brain pharmacokinetics and contribution to neurodegenerative disorders. Expert Opin Drug Metab Toxicol 2010;6:11611174.

25. Kirchheiner J, Nickchen K, Bauer M, Wong ML, Licinio J, Roots I, et al. Pharmacogenetics of antidepressants and antipsychotics: the contribution of allelic variations to the phenotype of drug response. Mol Psychiatry 2004;9:442473.

26. Singh AB, Bousman $\mathrm{CA}, \mathrm{Ng} \mathrm{CH}$, Byron K, Berk M. $A B C B 1$ polymorphism predicts escitalopram dose needed for remission in major depression. Transl Psychiatry 2012;2:e198.

27. Hicks JK, Swen JJ, Thorn CF, Sangkuhl K, Kharasch ED, Ellingrod VL, et al; Clinical Pharmacogenetics Implementation Consortium. Clinical Pharmacogenetics Implementation Consortium guideline for CYP2D6 and CYP2C19 genotypes and dosing of tricyclic antidepressants. Clin Pharmacol Ther 2013;93:402-408.

28. Preskorn S, Patroneva A, Silman H, Jiang Q, Isler JA, Burczynski ME, et al. Comparison of the pharmacokinetics of venlafaxine extended release and desvenlafaxine in extensive and poor cytochrome P450 2D6 metabolizers. J Clin Psychopharmacol 2009;29:39-43.

29. Nichols AI, Behrle JA, Richards LS, Parker VD, Posener JA, Fruncillo R, et al. The absolute bioavailability of desvenlafaxine in healthy subjects. J Bioequiv Availab 2012;4: 18-23.

30. Thase ME, Kornstein SG, Germain JM, Jiang Q, GuicoPabia C, Ninan PT. An integrated analysis of the efficacy of desvenlafaxine compared with placebo in patients with major depressive disorder. CNS Spectr 2009;14:144-154.

31. Linnet K, Ejsing TB. A review on the impact of P-glycoprotein on the penetration of drugs into the brain. Focus on psychotropic drugs. Eur Neuropsychopharmacol 2008; 18:157-169.

32. Hartz AM, Bauer B. ABC transporters in the CNS - an inventory. Curr Pharm Biotechnol 2011;12:656-673.

33. Juliano RL, Ling V. A surface glycoprotein modulating drug permeability in Chinese hamster ovary cell mutants. Biochim Biophys Acta 1976;455:152-162.

34. Chen CJ, Chin JE, Ueda K, Clark DP, Pastan I, Gottesman $\mathrm{MM}$, et al. Internal duplication and homology with bacterial transport proteins in the $m d r 1$ (P-glycoprotein) gene from multidrug-resistant human cells. Cell 1986;47:381-389. 
35. Callen DF, Baker E, Simmers RN, Seshadri R, Roninson IB. Localization of the human multiple drug resistance gene, MDR1, to 7q21.1. Hum Genet 1987;77:142-144.

36. Isenbarger TA, Carr CE, Johnson SS, Finney M, Church $\mathrm{GM}$, Gilbert $\mathrm{W}$, et al. The most conserved genome segments for life detection on Earth and other planets. Orig Life Evol Biosph 2008;38:517-533.

37. Eyal S, Ke B, Muzi M, Link JM, Mankoff DA, Collier AC, et al. Regional P-glycoprotein activity and inhibition at the human blood-brain barrier as imaged by positron emission tomography. Clin Pharmacol Ther 2010;87:579-585.

38. Hoffmeyer S, Burk O, von Richter O, Arnold HP, Brockmöller J, Johne A, et al. Functional polymorphisms of the human multidrug-resistance gene: multiple sequence variations and correlation of one allele with P-glycoprotein expression and activity in vivo. Proc Natl Acad Sci U S A 2000;97:3473-3478.

39. Kimchi-Sarfaty C, Oh JM, Kim IW, Sauna ZE, Calcagno $\mathrm{AM}$, Ambudkar SV, et al. A "silent" polymorphism in the MDR1 gene changes substrate specificity. Science 2007; 315:525-528.

40. Weiss J, Dormann SM, Martin-Facklam M, Kerpen CJ, Ketabi-Kiyanvash N, Haefeli WE. Inhibition of P-glycoprotein by newer antidepressants. J Pharmacol Exp Ther 2003; 305:197-204.

41. Uhr M, Tontsch A, Namendorf C, Ripke S, Lucae S, Ising $\mathrm{M}$, et al. Polymorphisms in the drug transporter geneABCBI predict antidepressant treatment response in depression. Neuron 2008;57:203-209.

42. Uhr M, Steckler T, Yassouridis A, Holsboer F. Penetration of amitriptyline, but not of fluoxetine, into brain is enhanced in mice with blood-brain barrier deficiency due to mdrla P-glycoprotein gene disruption. Neuropsychopharmacology 2000;22:380-387.

43. Wang JS, Zhu HJ, Gibson BB, Markowitz JS, Donovan JL, DeVane CL. Sertraline and its metabolite desmethylsertraline, but not bupropion or its three major metabolites, have high affinity for P-glycoprotein. Biol Pharm Bull 2008;31: 231-234.

44. Kato M, Fukuda T, Serretti A, Wakeno M, Okugawa G, Ikenaga Y, et al. ABCB1 (MDR1) gene polymorphisms are associated with the clinical response to paroxetine in patients with major depressive disorder. Prog Neuropsychopharmacol Biol Psychiatry 2008;32:398-404.

45. Lin KM, Chiu YF, Tsai IJ, Chen CH, Shen WW, Liu SC, et al. ABCB1 gene polymorphisms are associated with theseverity of major depressive disorder and its response to escitalopram treatment. Pharmacogenet Genomics 2011;21: 163-170.

46. Lee SH, Lee MS, Lee JH, Kim SW, Kang RH, Choi MJ, et al. MRP1 polymorphisms associated with citalopram response in patients with major depression. J Clin Psychopharmacol 2010;30:116-125.

47. Jia J, Yao P, Arif A, Fox PL. Regulation and dysregulation of 3'UTR-mediated translational control. Curr Opin Genet Dev 2013;23:29-34.

48. Bushra R, Aslam N, Khan AY. Food-drug interactions. Oman Med J 2011;26:77-83.

49. Tsai HH, Lin HW, Simon Pickard A, Tsai HY, Mahady GB.
Evaluation of documented drug interactions and contraindications associated with herbs and dietary supplements: a systematic literature review. Int J Clin Pract 2012;66: 1056-1078.

50. Akamine Y, Yasui-Furukori N, Ieiri I, Uno T. Psychotropic drug-drug interactions involving P-glycoprotein. CNS Drugs 2012;26:959-973.

51. Tod M, Nkoud-Mongo C, Gueyffier F. Impact of genetic polymorphism on drug-drug interactions mediated by cytochromes: a general approach. AAPS J 2013;15:1242-1252.

52. Crettol S, de Leon J, Hiemke C, Eap CB. Pharmacogenomics in psychiatry: from therapeutic drug monitoring to genomic medicine. Clin Pharmacol Ther 2014;95:254257.

53. Spudich A, Kilic E, Xing H, Kilic U, Rentsch KM, Wunderli-Allenspach $\mathrm{H}$, et al. Inhibition of multidrug resistance transporter-1 facilitates neuroprotective therapies after focal cerebral ischemia. Nat Neurosci 2006;9:487-488.

54. Hermann DM, Bassetti CL. Implications of ATP-binding cassette transporters for brain pharmacotherapies. Trends Pharmacol Sci 2007;28:128-134.

55. Kilic E, Spudich A, Kilic U, Rentsch KM, Vig R, Matter $\mathrm{CM}$, et al. ABCC1: a gateway for pharmacological compounds to the ischaemic brain. Brain 2008;131:2679-2689.

56. ElAli A, Hermann DM. Apolipoprotein E controls ATPbinding cassette transporters in the ischemic brain. Sci Signal 2010;3:ra72.

57. ElAli A, Urrutia A, Rubio-Araiz A, Hernandez-Jimenez M, Colado MI, Doeppner TR, et al. Apolipoprotein-E controls adenosine triphosphate-binding cassette transporters $A B C B 1$ and $A B C C 1$ on cerebral microvessels after methamphetamine intoxication. Stroke 2012:43:1647-1653.

58. ElAli A, Hermann DM. Liver X receptor activation enhances blood-brain barrier integrity in the ischemic brain and increases the abundance of ATP-binding cassette transporters $A B C B 1$ and $A B C C 1$ on brain capillary cells. Brain Pathol 2012;22:175-187.

59. Cartwright TA, Campos CR, Cannon RE, Miller DS. Mrp1 is essential for sphingolipid signaling to p-glycoprotein in mouse blood-brain and blood-spinal cord barriers. J Cereb Blood Flow Metab 2013;33:381-388.

60. Tao LY, Liang YJ, Wang F, Chen LM, Yan YY, Dai CL, et al. Cediranib (recentin, $A Z D 2171)$ reverses $A B C B 1-$ and $A B C C 1$-mediated multidrug resistance by inhibition of their transport function. Cancer Chemother Pharmacol 2009;64: 961-969.

61. Crisafulli C, Chiesa A, Han C, Lee SJ, Balzarro B, Andrisano $\mathrm{C}$, et al. Case-control association study of 36 single-nucleotide polymorphisms within 10 candidate genes for major depression and bipolar disorder. Psychiatry Res 2013;209:121-123.

62. Niitsu T, Fabbri C, Bentini F, Serretti A. Pharmacogenetics in major depression: a comprehensive meta-analysis. Prog Neuropsychopharmacol Biol Psychiatry 2013;45:183-194.

63. Thompson C, Hippman C, Hamilton SP. Psychiatrist attitudes towards pharmacogenetic testing, direct-to-consumer genetic testing, and integrating genetic counseling into psychiatric patient care. Psychiatry Res 2014. [Epub ahead of print]. 